\author{
Professor Singa Wang CHIU, PhD \\ Chung-Li CHOU, PhD \\ Dept. of Business Administration, Chaoyang University of Technology \\ Taichung ,Taiwan \\ Professor Hong-Dar LIN, PhD (Corresponding author) \\ E-mail: hdlin@cyut.edu.tw (H-D Lin) \\ Dept. of Industrial Engineering \& Management, Chaoyang University \\ of Technology, Taichung, Taiwan \\ Ming-Hon HWANG, PhD \\ Dept. of Marketing \& Logistics Management, Chaoyang University of \\ Technology, Taichung, Taiwan
}

\title{
EXPLORATION OF A MULTI-PRODUCT EPQ-BASED SYSTEM WITH OVERTIME AND QUALITY REASSURANCE
}

\begin{abstract}
In contemporary global marketplaces, buyers demand has to be satisfied with the timely provision of multiple products. Further, in real manufacturing settings, fabrication of imperfect items is inevitable owing to unanticipated issues; these items must be identified, separated, reworked or scrapped to keep product quality at the desired level. To cope with all these issues, producers must be able to make a flexible manufacturing plan that not only meets buyers' multi-product needs on time with perfect quality goods, but also has smooth fabrication schedules. Overtime is an effective alternative for increasing output rate and reducing completion time in batch production. Seeking to assist in production planning, this study explores a multi-product economic production quantity-based system with overtime and product quality reassurance, with the objective of finding the optimal stock refilling policy that minimizes total system cost. Mathematical techniques are employed to develop a precise model to represent the problem, find the total system cost, and determine a closed-form optimal common cycle length. A numerical illustration is provided to demonstrate that our model can reveal: (i) the influence of the variation in overtime-related factors on the system's variable cost, utilization, and total cost; (ii) the impact of difference in factors related to product quality on total system cost; and (iii) the combined impacts of changes in overtime and quality-related factors on various system parameters. Our investigation provides insights on system-related information that supports the planning and controlling functions of a realistic system.
\end{abstract}

Key words: Operations research, Production planning, Overtime, Rework, Failure in rework, Scrap.

JEL classifications: C02, M11, C44, C 61 
Singa Wang Chiu, Chung-Li Chou, Hong-Dar Lin, Ming-Hon Hwang

\section{Introduction}

The present work studies a multi-product economic production quantity (EPQ) -based system with overtime and product quality reassurance. In contemporary world marketplace, the nature of buyers' demand is timely needs of multiple types of products. Vergin and Lee [1] built a model to examine a single-machine stochastic demand multi-product fabrication scheduling problem. Six different rules for scheduling multi-product with varying parameters were conducted through simulation. The results indicated that a few well-known rules turned out to be expensive than others. In addition, it revealed that the well performed rule in a specific system depended on the following factors: (i) number of products; (ii) their distribution of demand; (iii) their share in capacity utilization; and (iv) their relating cost variables (e.g., setup, holding, stock-out etc.). Günther [2] studied the batch sizes for a single-facility capacitated multi-product problem. A few renowned period-by-period heuristics for determining the batch size were simulated in their study. Through comparison using numerical examples and attempts of proposing effective steps for improvement, they concluded that the cost performance of these investigated heuristics noticeably diverges, particularly in tight capacity constraints and less frequency in orders. Sox and Muckstadt [3] considered a multi-period multi-product fabrication planning with nondeterministic demand. Founded on the Lagrangian relaxation, authors proposed a sub-gradient optimization algorithm to resolve the problem. They offered a few computational outcomes to express how well their algorithm works in rolling-period planning as compared to the solution obtained from the optimal finite-period heuristic. Absi and Kedad-Sidhoum [4] examined a capacitated multi-product batch size problem considering safety stock, lost sales in stock-out situation, and setup times. Authors proposed a dynamic programming algorithm based on Lagrangian relaxation on capacity constraints to solve this NP-hard problem. Employing the Lagrangian heuristic along with a few adjusting algorithms, authors aimed to propose the upper bound to the problem. Then, by the use of experimental outcomes, authors demonstrated effectiveness of their approach. Rahmani et al. [5] developed an optimization model for solving a two-stage multi-item capacitated fabrication problem under uncertainty in manufacturing costs and demand. Authors built a model using the mixed-integer programming to obtain initial schedule and resolve the problem. Then, they improve the initial schedule aligned with potential uncertain incidences. Finally, a real world case was used to show performance and applicability of their model. Other studies [6-12] examined different characteristics of multi-product fabrication planning and systems.

To help increase output rate and shorten completion time in batch production, implementing the overtime option is an effective strategy. Conley [13] studied a production scheduling problem considering overtime option, wherein scheduling the processes of multiple products in different departments under overtime shifts is explored. Multi-stage optimization procedures based on Monte Carlo theory was used to solve this nonlinear scheduling problem which incorporating the 
Exploration of a Multi-Product EPQ-Based System with Overtime and Quality Reassurance

quantitative factor of worker fatigue. Shiftan and Wilson [14] explored a workforce planning problem focusing on examination of the interrelationships among overtime, absence, and service reliability. Based on the dynamic nature of in-time activities allocation, authors built a disaggregate model to investigate the relationship between absence and overtime. Real-life data was used to test the hypothesis of 'overtime may encourage absence', and authors concluded that absence is independent from overtime option. Further analysis using the real data, indicated that overtime and reliability has a significant linear relationship which facilitate the overtime decision-making. Schank [15] compared efficiencies between overtime implemented plants and standard-time only plants using real-life (IAB Establishment Panel) data for a period of time (1995 to 2000). Author utilized the difference between feasible and real outputs from the known inputs as measures for efficiency to compare these two types of plants. Upon completion of the comparisons, author concluded that no significant difference was found in terms of the efficiency measures from these different types of plants. Campbell [16] examined a service workforce scheduling problem considering on-call overtime option. Author developed models for shift scheduling incorporating such a specific overtime type which can be applied to various service environments. On-call overtime scenarios for single- and multi-department were examined, and research result indicated that insignificant cost savings derived from the on-call overtime, however, if overtime is provided by the external agency, then it becomes costly as compared to that by the internal workers. Also, service quality and morale is significantly better when using on-call overtime. Extra studies [17-19] explored fabrication scheduling problem with various overtime/adjusted rate features.

In real manufacturing settings, fabrication of imperfect items is inevitable owing to unanticipated issues; these items have to be identified, separated, reworked or scrapped to keep product quality at the desired level. Quite a few studies [20-29] examined various features of imperfect/unreliable production systems and their follow-up quality reassurance matters. This study explores a multi-product EPQ-based system with overtime and product quality reassurance. Prior works paid little attention to the joint effects of overtime and quality ensured matters on multi- product system, the present work aims to bridge the gap.

\section{Description of the proposed multi-product EPQ-based system}

A multi-product EPQ-based system considering overtime and product quality reassurance is examined. Problem statement is provided below: an EPQ-based batch production plan for $L$ distinctive products is arranged on a machine using a rotation cycle time rule. Under such a rule, each product $i$ (where $i$ equals to 1 , $2, \ldots, L)$ is replenished once in sequence in a fabrication cycle. Besides, aiming to reduce the cycle length, an overtime policy is incorporated in this batch production. The accelerated output rate of product $i$ is $P_{1 \mathrm{iA}}$, which is different from its standard annual rate $P_{1 \mathrm{i}}$, and the relationship between them is as follows:

$$
P_{1 i \mathrm{~A}}=\left(1+\alpha_{1 i}\right) P_{1 i}
$$

where $\alpha_{1 i}$ denotes extra percentage of output rate of product $i$ due to implementing 
overtime plan (where $\alpha_{1 i}>0$ ).

The fabrication process of each product $i$ is imperfect, a $x_{i}$ proportion of nonconforming items may be fabricated randomly at an annual rate $d_{1 i \mathrm{~A}}$. It is assumed that a fairly constant proportion $\theta_{1 i}$ among nonconforming items (where 0 $\left.<=\theta_{1 i}<=1\right)$ is considered scrap and will be disposed at a unit removal cost $C_{\mathrm{S} i}$. The other $\left(1-\theta_{1 i}\right)$ portion is treated to be rework-able. The process of reworking product $i$ starts right away when uptime of product $i$ ends in each cycle, also at an expeditious rate of $P_{2 i \mathrm{~A}}(\mathbf{F i g} . \mathbf{1})$. The following is the relationship between $P_{2 i \mathrm{~A}}$ and $P_{2 i}$ :

$$
P_{2 i \mathrm{~A}}=\left(1+\alpha_{1 i}\right) P_{2 i}
$$

As a result, more expensive costs are associated with overtime implementation in the processes of production and rework, and their relationships with standard cost parameters are as follows:

$$
\begin{aligned}
K_{i \mathrm{~A}} & =\left(1+\alpha_{2 i}\right) K_{i} \\
C_{i \mathrm{~A}} & =\left(1+\alpha_{3 i}\right) C_{i} \\
C_{\mathrm{R} i \mathrm{~A}} & =\left(1+\alpha_{3 i}\right) C_{\mathrm{R} i}
\end{aligned}
$$

where $K_{i \mathrm{~A}}, C_{i \mathrm{~A}}$, and $C_{\mathrm{RiA}}$ are the setup, unit production, and unit rework costs of product $i$ with overtime implementing in uptime and rework time; $K_{i}, C_{i}$, and $C_{\mathrm{R} i}$ represent the standard setup, unit production, and unit rework costs of product $i$ (without overtime option during uptime and rework time); and $\alpha_{2 i}$ and $\alpha_{3 i}$ denote increased proportion of cost due to overtime option in comparison with standard cost (both $\alpha_{2 i}>0$ and $\alpha_{3 i}>0$ ). Additional notations used in this research are given in Table A - 1 in Appendix - A.

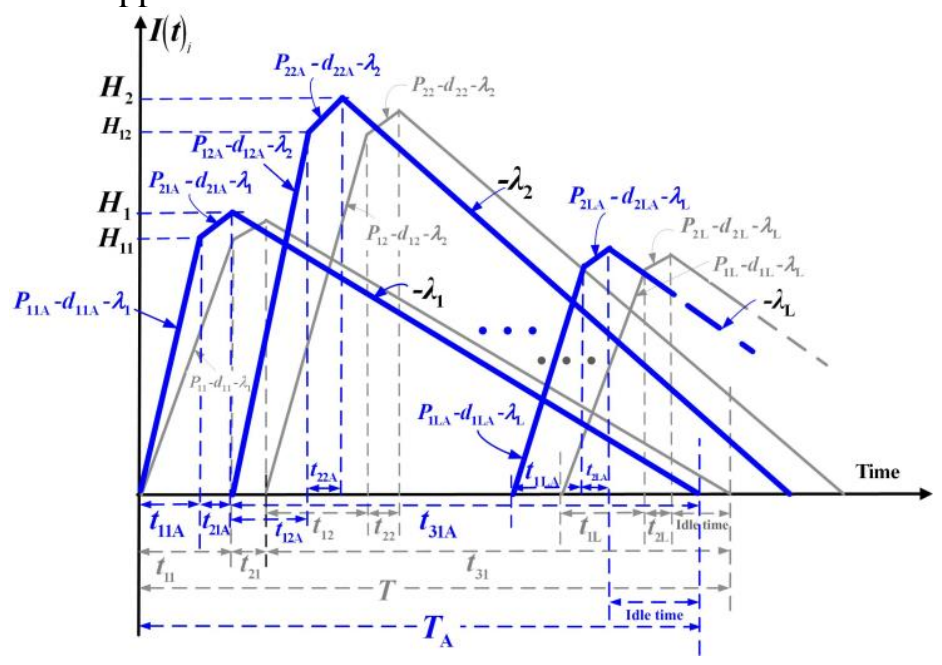

Figure 1. Standing of inventory of completed product $i$ in the proposed multi-product system with overtime and quality reassurance (in blue) in comparison with the same system without overtime (in grey) 
Exploration of a Multi-Product EPQ-Based System with Overtime and Quality Reassurance

Upon completion of uptime $t_{1 i \mathrm{~A}}$ of each product $i$, the highest standing of defective items is as shown in Eq. (6). In the process of rework of product $i$, a fairly constant proportion $\theta_{2 i}$ (where $0<=\theta_{2 i}<=1$ ) among reworked items fails and will be scrapped (see Figure 2).

$$
d_{1 i \mathrm{~A}} t_{1 i \mathrm{~A}}=x_{i} P_{1 \mathrm{~A}} t_{1 i \mathrm{~A}}=x_{i} Q_{i}
$$

where

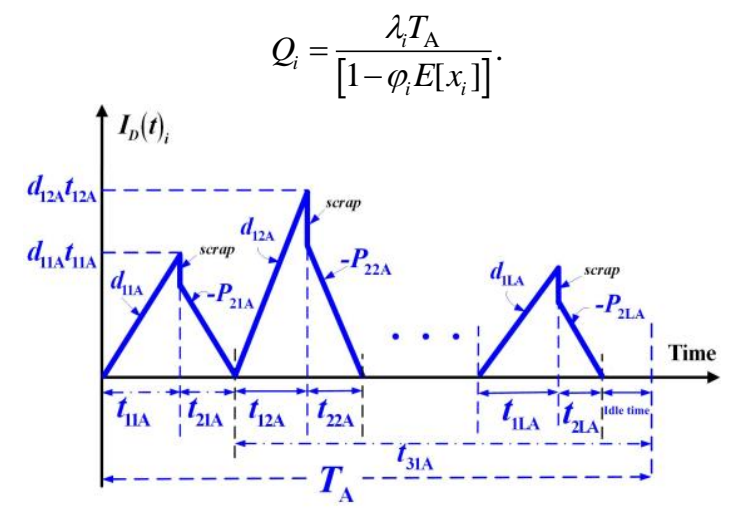

Figure 2. Standing of inventory of nonconforming product $i$ in the proposed multi-product system with overtime and quality reassurance

The standing of scrapped stocks of product $i$ including those identified in $t_{1 i \mathrm{~A}}$ and $t_{2 i \mathrm{~A}}$ are exhibited in Figure 3 and maximum scrap items of each product $i$ is exposed as follows:

$$
d_{1 i \mathrm{~A}} \theta_{1 i} t_{1 i \mathrm{~A}}+d_{2 i \mathrm{~A}} t_{2 i \mathrm{~A}}=\varphi_{i} x_{i} Q_{i}=\left[\theta_{1 i}+\theta_{2 i}\left(1-\theta_{1 i}\right)\right] x_{i} Q_{i}
$$

where

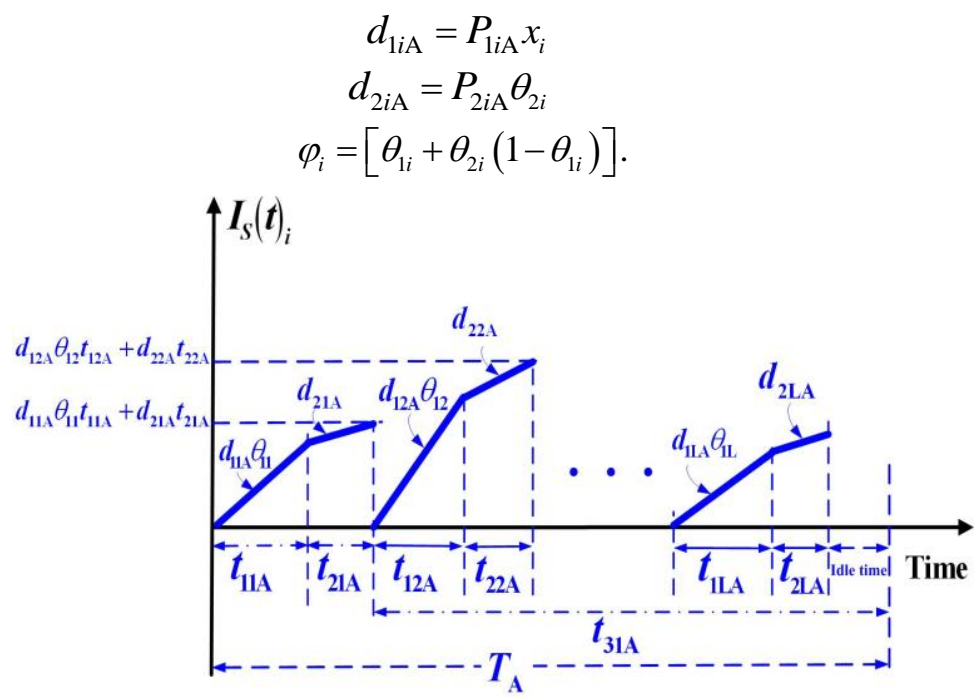

Figure 3. Standing of inventory of scrapped product $i$ in the proposed multi-product system with overtime and quality reassurance 
Singa Wang Chiu, Chung-Li Chou, Hong-Dar Lin, Ming-Hon Hwang

Additional formulas can be observed from Fig. 1 as shown in Eqs. (12) to (17):

$$
\begin{gathered}
t_{1 i \mathrm{~A}}=\frac{Q_{i}}{P_{1 i \mathrm{~A}}} \\
t_{2 i \mathrm{~A}}=\frac{x_{i} Q_{i}\left(1-\theta_{1 i}\right)}{P_{2 i \mathrm{~A}}} \\
H_{1 i}=\left(P_{1 i \mathrm{~A}}-d_{1 i \mathrm{~A}}-\lambda_{i}\right) t_{1 i \mathrm{~A}} \\
t_{3 i \mathrm{~A}}=\frac{H_{i}}{\lambda_{i}} \\
H_{i}=H_{1 i}+\left(P_{2 i \mathrm{~A}}-d_{2 i \mathrm{~A}}-\lambda_{i}\right) t_{2 i \mathrm{~A}} \\
T_{\mathrm{A}}=t_{1 i \mathrm{~A}}+t_{2 i \mathrm{~A}}+t_{3 i \mathrm{~A}}
\end{gathered}
$$

Moreover, the stock-out conditions are not allowed in the proposed EPQ model, so Eq. (18) must hold; and the capacity of the single machine used in the proposed EPQ model ought to be adequate to perform production and rework tasks of every product $i$ [30], that is Eq. (19) must also hold.

$$
\begin{gathered}
\left(P_{1 i \mathrm{~A}}-d_{1 \mathrm{iA}}-\lambda_{i}\right)>0 \\
\sum_{i=1}^{L}\left\{\left[\frac{\lambda_{i}}{\left[1-\varphi_{i} E\left[x_{i}\right]\right] P_{1 \mathrm{~A}}}\right]+\left[\frac{\lambda_{i}\left[E\left[x_{i}\right]\left(1-\theta_{1 i}\right)\right]}{\left[1-\varphi_{i} E\left[x_{i}\right]\right] P_{2 i \mathrm{~A}}}\right]\right\}<1
\end{gathered}
$$

\section{Cost analysis of the proposed multi-product EPQ model}

Cost contributors of the proposed multi-product EPQ model include the following:

(1) Summation of $L$ products' production variable and setup costs

$$
\sum_{i=1}^{L}\left(C_{i \mathrm{~A}} Q_{i}+K_{i \mathrm{~A}}\right)
$$

(2) Summation of $L$ products' rework and disposal costs

$$
\sum_{i=1}^{L}\left[C_{\mathrm{RiA}}\left(x_{i} Q_{i}\right)\left(1-\theta_{1 i}\right)+C_{\mathrm{S} i}\left(x_{i} Q_{i}\right) \varphi_{i}\right]
$$

(3) Summation of $L$ products' holding costs during rework process

$$
\sum_{i=1}^{L}\left[h_{1 i} \frac{P_{2 i \mathrm{~A}} t_{2 i \mathrm{~A}}}{2}\left(t_{2 i \mathrm{~A}}\right)\right]
$$

(4) Summation of $L$ products' holding costs (comprising completed and nonconforming items)

$$
\sum_{i=1}^{L}\left\{h_{i}\left[\frac{H_{1 i}+d_{1 \mathrm{~A}} t_{1 \mathrm{~A}}}{2}\left(t_{1 \mathrm{~A}}\right)+\frac{H_{1 i}+H_{i}}{2}\left(t_{2 i \mathrm{~A}}\right)+\frac{H_{i}}{2}\left(t_{3 i \mathrm{~A}}\right)\right]\right\}
$$

Consequently, $T C\left(T_{\mathrm{A}}\right)$ is as follows: 
Exploration of a Multi-Product EPQ-Based System with Overtime and Quality Reassurance

$$
T C\left(T_{\mathrm{A}}\right)=\sum_{i=1}^{L}\left\{\begin{array}{l}
C_{i \mathrm{~A}} Q_{i}+K_{i \mathrm{~A}}+C_{\mathrm{RiA}}\left(x_{i} Q_{i}\right)\left(1-\theta_{1 i}\right)+C_{\mathrm{Si}}\left(x_{i} Q_{i}\right) \varphi_{i}+h_{1 i} \frac{P_{2 i \mathrm{~A}} t_{2 i \mathrm{~A}}}{2}\left(t_{2 i \mathrm{~A}}\right) \\
+h_{i}\left[\frac{H_{1 i}+d_{1 \mathrm{~A}} t_{1 i \mathrm{~A}}}{2}\left(t_{1 \mathrm{~A}}\right)+\frac{H_{1 i}+H_{i}}{2}\left(t_{2 i \mathrm{~A}}\right)+\frac{H_{i}}{2}\left(t_{3 i \mathrm{~A}}\right)\right]
\end{array}\right\}
$$

Substitute Eqs. (1) to (17) in Eq. (24) and apply $E\left[x_{i}\right]$ to manage arbitrariness of $x_{i}$, the following expected annual system cost $E\left[T C U\left(T_{\mathrm{A}}\right)\right]$ can be determined after with further derivations:

$$
\begin{aligned}
E & {\left[T C U\left(T_{\mathrm{A}}\right)\right]=\frac{E\left[T C\left(T_{\mathrm{A}}\right)\right]}{E\left[T_{\mathrm{A}}\right]} } \\
& =\sum_{i=1}^{L}\left\{\begin{array}{l}
{\left[\left(1+\alpha_{3 i}\right) C_{i}\right] E_{0 i}+\frac{\left(1+\alpha_{2 i}\right) K_{i}}{T_{\mathrm{A}}}+\left[\left(1+\alpha_{3 i}\right) C_{\mathrm{Ri}}\right] E_{0 i} E\left[x_{i}\right]\left(1-\theta_{1 i}\right)} \\
+C_{\mathrm{Si}} E_{0 i} E\left[x_{i}\right] \varphi_{i}+\frac{T_{\mathrm{A}} E\left[x_{i}\right]^{2}\left(1-\theta_{1 i}\right) E_{0 i}^{2}}{2\left(1+\alpha_{1 i}\right) P_{2 i}}\left[h_{1 i}\left(1-\theta_{1 i}\right)-h_{i}\right]+\frac{h_{i} T_{\mathrm{A}}\left(\lambda_{i}+E_{0 i}^{2} E_{1 i}\right)}{2}
\end{array}\right\}
\end{aligned}
$$

where $E_{0 i}=\frac{\lambda_{i}}{1-\varphi_{i} E\left[x_{i}\right]} ; E_{1 i}=\left\{\frac{\left[2 E\left[x_{i}\right] \varphi_{i}-1\right]}{\left(1+\alpha_{1 i}\right) P_{1 i}}+\frac{E\left[x_{i}\right]^{2} \varphi_{i}\left(1-\theta_{1 i}\right)}{\left(1+\alpha_{1 i}\right) P_{2 i}}\right\}$.

\subsection{Determining the optimal $T_{\mathrm{A}}$ *}

The first- and the second-derivative of $E\left[T C U\left(T_{\mathrm{A}}\right)\right]$ were first calculated as follows:

$$
\begin{gathered}
\frac{d E\left[T C U\left(T_{\mathrm{A}}\right)\right]}{d T_{\mathrm{A}}}=\sum_{i=1}^{L}\left\{-\frac{\left(1+\alpha_{2 i}\right) K_{i}}{T_{\mathrm{A}}^{2}}+\frac{E\left[x_{i}\right]^{2}\left(1-\theta_{1 i}\right) E_{0 i}^{2}}{2\left(1+\alpha_{1 i}\right) P_{2 i}}\left[h_{1 i}\left(1-\theta_{1 i}\right)-h_{i}\right]+\frac{h_{i}\left(\lambda_{i}+E_{0 i}^{2} E_{1 i}\right)}{2}\right\} \\
\frac{d^{2} E\left[T C U\left(T_{\mathrm{A}}\right)\right]}{d T_{\mathrm{A}}^{2}}=\sum_{i=1}^{L} 2\left[\frac{\left(1+\alpha_{2 i}\right) K_{i}}{T_{\mathrm{A}}^{3}}\right]>0
\end{gathered}
$$

It can be seen that Eq. (27) is positive for $T_{\mathrm{A}},\left(1+\alpha_{2 i}\right)$, and $K_{i}$ are all positive. So, we know that $E\left[T C U\left(T_{\mathrm{A}}\right)\right]$ is convex for all $T_{\mathrm{A}}$ other than zero, and it has minimum values. To locate $T_{\mathrm{A}} *$ that minimizes $E\left[T C U\left(T_{\mathrm{A}}\right)\right]$, we let the first-derivative equal to zero and solve for $T_{\mathrm{A}}{ }^{*}$.

$$
\sum_{i=1}^{L}\left\{-\frac{\left(1+\alpha_{2 i}\right) K_{i}}{T_{\mathrm{A}}^{2}}+\frac{E\left[x_{i}\right]^{2}\left(1-\theta_{1 i}\right) E_{0 i}^{2}}{2\left(1+\alpha_{1 i}\right) P_{2 i}}\left[h_{1 i}\left(1-\theta_{1 i}\right)-h_{i}\right]+\frac{h_{i}\left(\lambda_{i}+E_{0 i}^{2} E_{1 i}\right)}{2}\right\}=0
$$

or

$$
\sum_{i=1}^{L}\left[\left(1+\alpha_{2 i}\right) K_{i}\right]=T_{\mathrm{A}}^{2} \cdot \sum_{i=1}^{L}\left\{\frac{E\left[x_{i}\right]^{2}\left(1-\theta_{1 i}\right) E_{0 i}^{2}}{2\left(1+\alpha_{1 i}\right) P_{2 i}}\left[h_{1 i}\left(1-\theta_{1 i}\right)-h_{i}\right]+\frac{h_{i}\left(\lambda_{i}+E_{0 i}^{2} E_{1 i}\right)}{2}\right\}
$$

or 
Singa Wang Chiu, Chung-Li Chou, Hong-Dar Lin, Ming-Hon Hwang

$$
T_{\mathrm{A}}^{*}=\sqrt{\frac{2 \sum_{i=1}^{L}\left[K_{i}\left(1+\alpha_{2 i}\right)\right]}{\sum_{i=1}^{L}\left\{\frac{E\left[x_{i}\right]^{2}\left(1-\theta_{1 i}\right) E_{0 i}^{2}}{\left(1+\alpha_{1 i}\right) P_{2 i}}\left[h_{1 i}\left(1-\theta_{1 i}\right)-h_{i}\right]+h_{i}\left(\lambda_{i}+E_{0 i}^{2} E_{1 i}\right)\right\}}}
$$

\subsection{Effect of summation of $L$ products' setup times on $T_{A}$}

In general, if summation of $L$ products' setup times is smaller than idle time (see Fig. 1), then the aforementioned $T_{\mathrm{A}} *$ (i.e., Eq. (30)) is valid as the optimal cycle time. However, if machine utilization goes higher and the resulting system's idle time becomes smaller, then it will be a proper decision process by calculating the following $T_{\min }$ (see Appendix-B for details in calculation) and select $\max \left(T_{\mathrm{A}}{ }^{*}, T_{\min }\right)$ as $T_{\mathrm{A}}$ to the problem [30]:

$$
T_{\min }=\frac{\sum_{i=1}^{L}\left(S_{i}\right)}{1-\sum_{i=1}^{L}\left[\frac{\lambda_{i}}{P_{1 \mathrm{~A}}\left[1-\varphi_{i} E\left[x_{i}\right]\right]}+\frac{E\left[x_{i}\right]\left(1-\theta_{1 i}\right) \lambda_{i}}{P_{2 \mathrm{~A}}\left[1-\varphi_{i} E\left[x_{i}\right]\right]}\right.}
$$

\section{Numerical Example}

A numerical example considering five distinct products is offered in this section to demonstrate the applicability of our proposed multi-product system with overtime and quality reassurance. Assumptions of parameters are given in Table C-1 (see Appendix C). We start with calculations of Eqs. (30) and (25), $T_{\mathrm{A}} *=0.6248$ and optimal cost $E\left[T C U\left(T_{\mathrm{A}} *\right)\right]=\$ 2,530,854$. Table 1 exhibits further explorative outcomes on the effects of differences in $\overline{\alpha_{1}}$ on various factors of the proposed model.

\begin{tabular}{|c|c|c|c|c|c|c|c|c|c|c|c|c|}
\hline$\overline{\alpha_{1}}$ & $\overline{\alpha_{2}}$ & $T_{\mathrm{A}}{ }^{*}$ & $\begin{array}{c}E\left[T C U\left(T_{\mathrm{A}}{ }^{*}\right)\right] \\
(1)\end{array}$ & $\begin{array}{c}\% \\
\text { increase }\end{array}$ & $\begin{array}{l}\text { Cost for } \\
\text { quality } \\
\text { reassure- } \\
\text { ance }(2)\end{array}$ & $\begin{array}{c}\% \\
(2) /(1)\end{array}$ & $\overline{\alpha_{3}}$ & $\begin{array}{l}\text { Variable } \\
\text { production } \\
\text { cost (3) }\end{array}$ & $\begin{array}{c}\% \\
(3) /(1)\end{array}$ & $\begin{array}{c}\% \\
\text { increase }\end{array}$ & $\begin{array}{l}\text { Sum of } \\
\text { machine } \\
\text { utilization }\end{array}$ & $\begin{array}{c}\% \\
\text { decline }\end{array}$ \\
\hline 0 & & & & & & & & & & & & \\
\hline 0.1 & & & & $59 \%$ & & & & & & & & 80 \\
\hline .2 & & & & $19 \%$ & 7 & 6. & & & $\%$ & 10. & & $67 \%$ \\
\hline 13 & & & & $77 \%$ & & & & & & 15.0 & & r \\
\hline 0.40 & 0.0 & 0.6 & & $\%$ & $\$$ & 6. & 0 & & $5 \%$ & $0 \%$ & & $-28.57 \%$ \\
\hline 0.50 & & 0.6248 & 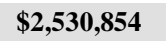 & $2.94 \%$ & $\$ 15$ & $6.24 \%$ & 0.25 & & $1 \%$ & $25.00 \%$ & & $-33.33 \%$ \\
\hline 0.60 & & & & $27.52 \%$ & & & 0.3 & & 87.7 & & & $-37.50 \%$ \\
\hline 0.7 & & & & & & & 0.3 & & & & & -41 \\
\hline 0.8 & & & & & & & & & & & & $-44.44 \%$ \\
\hline 0.90 & 0.18 & 0.6447 & $\$ 2,907,684$ & $41.24 \%$ & $\$ 171,791$ & $5.91 \%$ & 0.45 & $\$ 2,517,285$ & $88.35 \%$ & $45.00 \%$ & 0.3462 & $-47.37 \%$ \\
\hline
\end{tabular}

Table 1: Effects of differences in $\overline{\alpha_{1}}$ on various factors of the proposed model 
Exploration of a Multi-Product EPQ-Based System with Overtime and Quality Reassurance

\begin{tabular}{lllllllllllll}
\hline 1.00 & 0.20 & 0.6497 & $\$ 3,001,808$ & $45.81 \%$ & $\$ 175,280$ & $5.84 \%$ & 0.50 & $\$ 2,605,872$ & $88.53 \%$ & $50.00 \%$ & 0.3289 & $-50.00 \%$ \\
1.10 & 0.22 & 0.6547 & $\$ 3,095,906$ & $50.38 \%$ & $\$ 178,773$ & $5.77 \%$ & 0.55 & $\$ 2,694,459$ & $88.70 \%$ & $55.00 \%$ & 0.3132 & $-52.38 \%$ \\
1.20 & 0.24 & 0.6597 & $\$ 3,189,977$ & $54.95 \%$ & $\$ 182,269$ & $5.71 \%$ & 0.60 & $\$ 2,783,046$ & $88.87 \%$ & $60.00 \%$ & 0.2990 & $-54.55 \%$ \\
1.30 & 0.26 & 0.6646 & $\$ 3,284,025$ & $59.52 \%$ & $\$ 185,769$ & $5.66 \%$ & 0.65 & $\$ 2,871,634$ & $89.02 \%$ & $65.00 \%$ & 0.2860 & $-56.52 \%$ \\
1.40 & 0.28 & 0.6696 & $\$ 3,378,050$ & $64.09 \%$ & $\$ 189,271$ & $5.60 \%$ & 0.70 & $\$ 2,960,221$ & $89.16 \%$ & $70.00 \%$ & 0.2741 & $-58.33 \%$ \\
1.50 & 0.30 & 0.6745 & $\$ 3,472,055$ & $68.66 \%$ & $\$ 192,775$ & $5.55 \%$ & 0.75 & $\$ 3,048,808$ & $89.30 \%$ & $75.00 \%$ & 0.2631 & $-60.00 \%$ \\
1.60 & 0.32 & 0.6794 & $\$ 3,566,039$ & $73.22 \%$ & $\$ 196,282$ & $5.50 \%$ & 0.80 & $\$ 3,137,395$ & $89.43 \%$ & $80.00 \%$ & 0.2530 & $-61.54 \%$ \\
1.70 & 0.34 & 0.6843 & $\$ 3,660,005$ & $77.79 \%$ & $\$ 199,790$ & $5.46 \%$ & 0.85 & $\$ 3,225,982$ & $89.56 \%$ & $85.00 \%$ & 0.2436 & $-62.96 \%$ \\
1.80 & 0.36 & 0.6891 & $\$ 3,753,953$ & $82.35 \%$ & $\$ 203,301$ & $5.42 \%$ & 0.90 & $\$ 3,314,569$ & $89.67 \%$ & $90.00 \%$ & 0.2349 & $-64.29 \%$ \\
1.90 & 0.38 & 0.6939 & $\$ 3,847,883$ & $86.91 \%$ & $\$ 206,812$ & $5.37 \%$ & 0.95 & $\$ 3,403,157$ & $89.79 \%$ & $95.00 \%$ & 0.2268 & $-65.52 \%$ \\
2.00 & 0.40 & 0.6987 & $\$ 3,941,797$ & $91.47 \%$ & $\$ 210,326$ & $5.34 \%$ & 1.00 & $\$ 3,491,744$ & $89.90 \%$ & $100.00 \%$ & 0.2193 & $-66.67 \%$ \\
\hline
\end{tabular}

Effects of changes in ratio of average overtime unit cost over average regular unit $\operatorname{cost}\left(\overline{C_{\mathrm{A}}} / \bar{C}\right)$ on variable production cost for each product are explored and the outcomes are depicted in Figure 4. It is noted that each product's variable cost notably increases, as the ratio of $\overline{C_{\mathrm{A}}} / \bar{C}$ goes up.

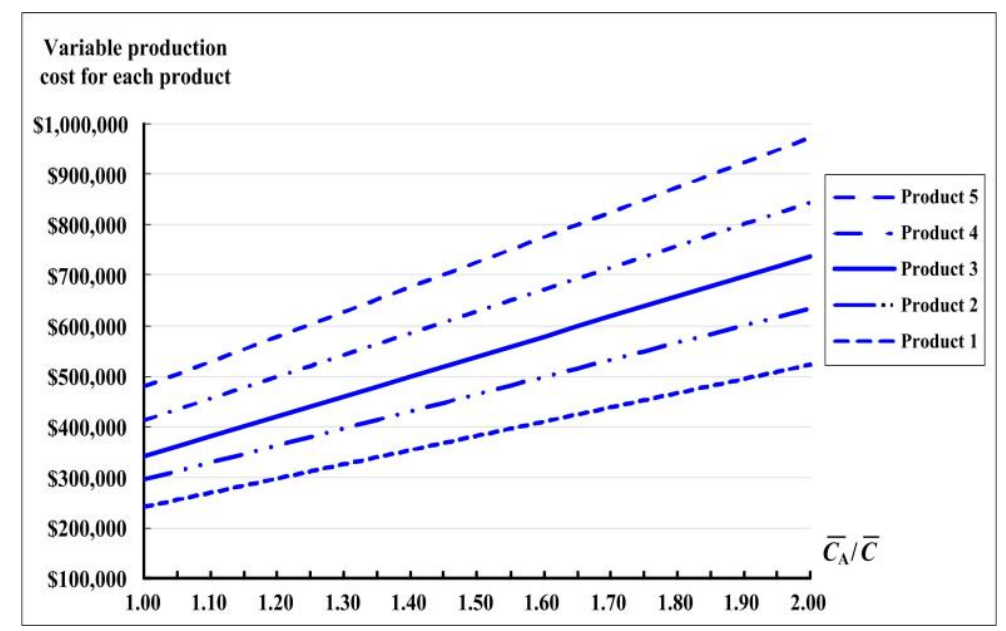

Figure 4. Effects of changes in ratio of $\overline{C_{\mathrm{A}}} / \bar{C}$ on variable production cost for each product

Examining the factor of product quality reassurance effects on the proposed system, from Table 1 we get to know that the cost for quality reassurance is $\$ 157,896$ (for at $\overline{\alpha_{1}}=0.5$ ), and it is $6.24 \%$ of system cost. Further, Figure 5 displays analytical impact of differences in average overall scrap rate $\bar{\varphi}$ along with various average defective rates $\bar{x}$ on the optimal sum of expected system cost $E\left[T C U\left(T_{\mathrm{A}} *\right)\right]$. It indicates that $E\left[T C U\left(T_{\mathrm{A}}{ }^{*}\right)\right]$ raises, as $\bar{\varphi}$ increases; and especially, as $\bar{x}$ goes higher, the expected system cost boosts up considerably. 
Singa Wang Chiu, Chung-Li Chou, Hong-Dar Lin, Ming-Hon Hwang

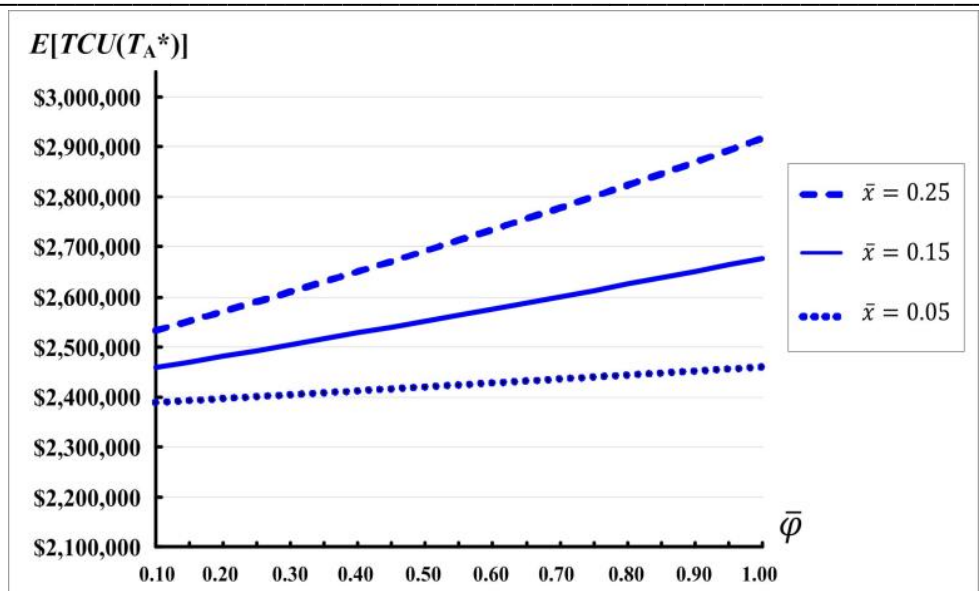

Figure 5. Impact of differences in $\bar{\varphi}$ along with various $\bar{x}$ on $E\left[T C U\left(T_{\mathrm{A}}^{*}\right)\right]$

In addition, Figure 6 illustrates the influences of variations in average added percentage of output rate $\bar{\alpha}_{1}$ (due to overtime option) along with various average overall scrap rate $\bar{\varphi}$ on $E\left[T C U\left(T_{\mathrm{A}} *\right)\right]$. It specifies that $E\left[T C U\left(T_{\mathrm{A}}{ }^{*}\right)\right]$ boosts up significantly, as $\overline{\alpha_{1}}$ raises; and it increases slightly, as $\bar{\varphi}$ goes up.

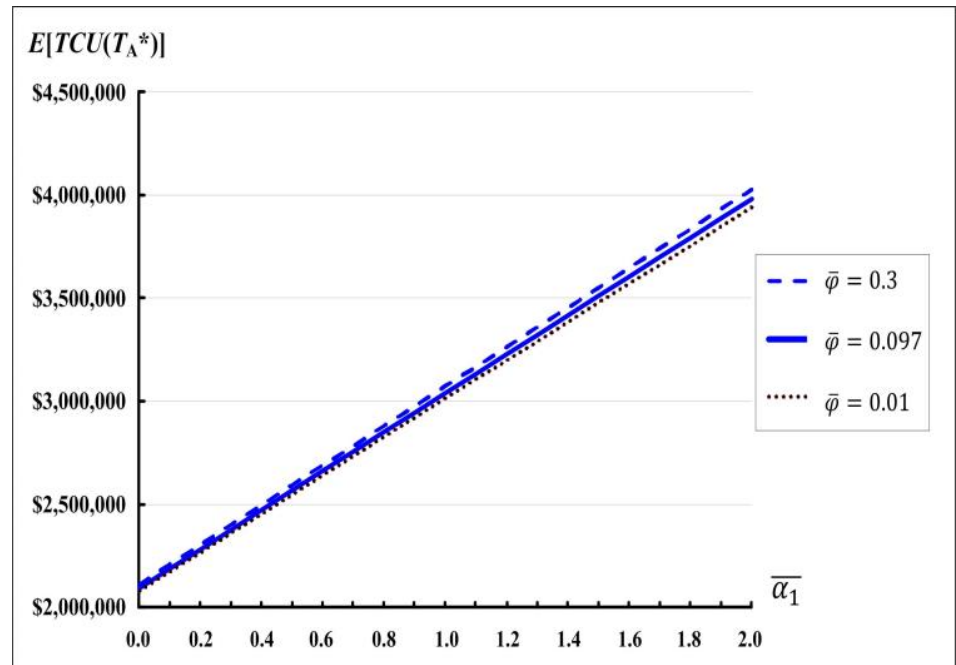

Figure 6. Influences of variations in $\overline{\alpha_{1}}$ along with various $\bar{\varphi}$ on $\boldsymbol{E}\left[\boldsymbol{T C U}\left(\boldsymbol{T}_{\mathrm{A}}{ }^{*}\right)\right]$ Exploratory outcome on effects of deviations in $T_{\mathrm{A}}$ on diverse cost contributors to the proposed system is presented Figure 7. It shows that as $T_{\mathrm{A}}$ deviates from its optimal point (i.e., 0.6248) and moves up, system's quality cost goes up insignificantly; but, inventory holding cost raises drastically; conversely, the setup cost declines severely. It also verifies that at $T_{\mathrm{A}}{ }^{*}, E\left[T C U\left(T_{\mathrm{A}}{ }^{*}\right)\right]=\$ 2,530,854$. 
Exploration of a Multi-Product EPQ-Based System with Overtime and Quality Reassurance

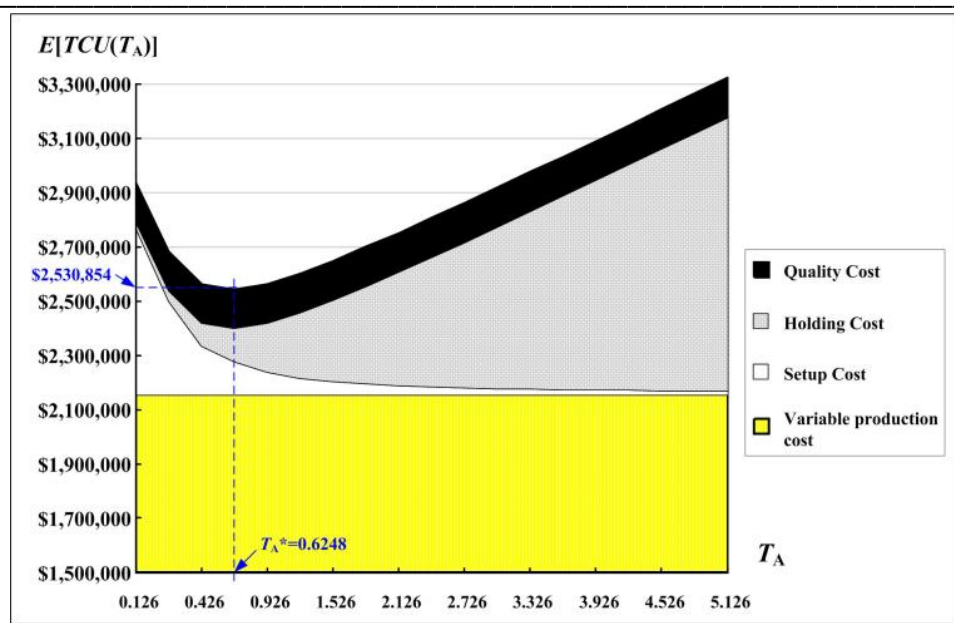

Figure 7. Effects of deviations in $T_{\mathrm{A}}$ on $E\left[T C U\left(T_{\mathrm{A}}\right)\right]$ and diverse system cost contributors

Looking into the overtime effects on the proposed system, Figure 8 exhibits the impact of changes in ratio of average overtime production output rate over average standard output rate $\overline{P_{1 \mathrm{~A}}} / \overline{P_{1}}$ on the sum of machine utilization. It specifies that the sum of utilization decreases radically, as the ratio of $\overline{P_{1 \mathrm{~A}}} / \overline{P_{1}}$ increases; and at $\overline{P_{1 \mathrm{~A}}} / \bar{P}_{1}=1.5$ (as assumed in our example), the sum of utilization falls to 0.4385 (from 0.6578, see Table 1 for details).

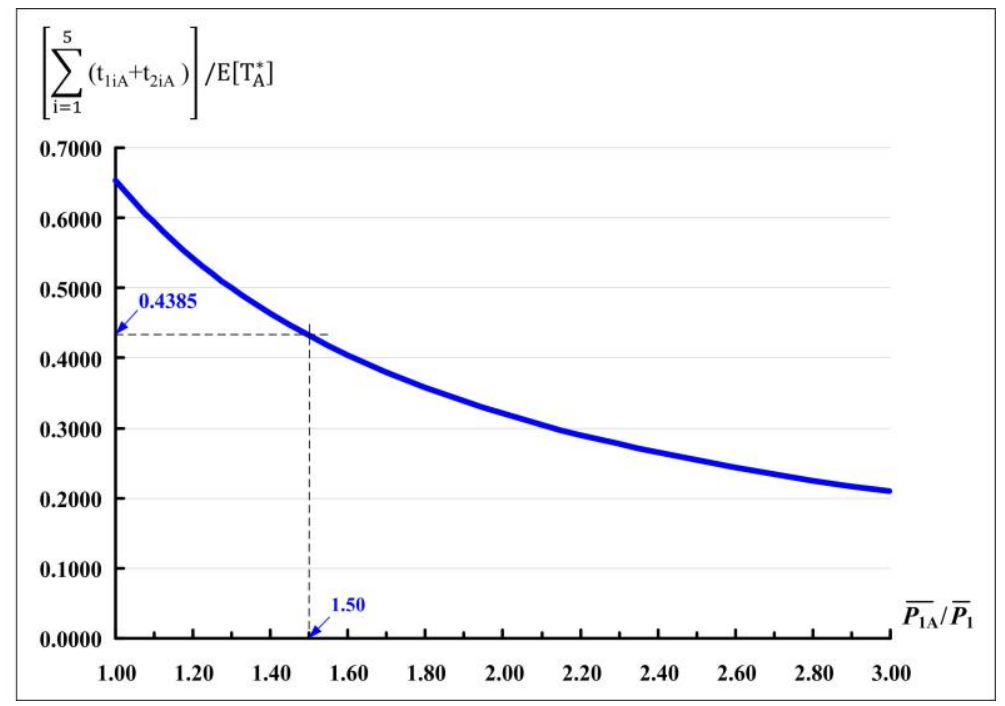

Figure 8. Impact of changes in ratio of $\overline{P_{1 \mathrm{~A}}} / \overline{P_{1}}$ on the sum of utilization 
Singa Wang Chiu, Chung-Li Chou, Hong-Dar Lin, Ming-Hon Hwang

On the other hand, the cost for reducing utilization is also investigated and the outcome is depicted in Figure 9. It points out that as ratio of $\overline{P_{1 \mathrm{~A}}} / \bar{P}_{1}$ increases, $E\left[T C U\left(T_{\mathrm{A}}{ }^{*}\right)\right]$ notably goes up; and it reconfirms that $E\left[T C U\left(T_{\mathrm{A}}{ }^{*}\right)\right]=\$ 2,530,854$ when $\overline{P_{1 \mathrm{~A}}} / \overline{P_{1}}=1.5$ (as assumed in our example).

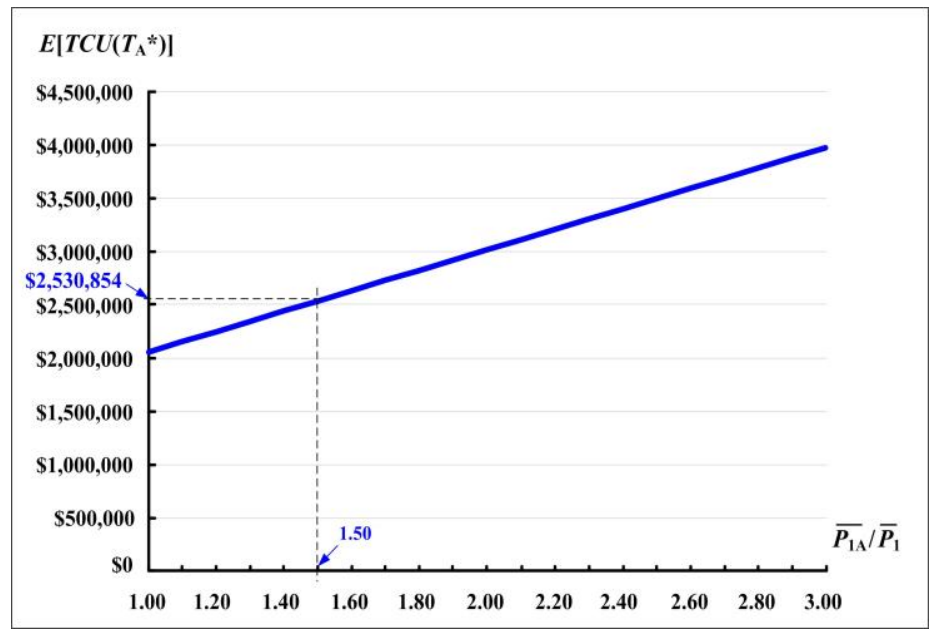

Figure 9. Effect of differences in ratio of $\overline{P_{1 \mathrm{~A}}} / \overline{P_{1}}$ on $\boldsymbol{E}\left[\boldsymbol{T C U}\left(\boldsymbol{T}_{\mathrm{A}}{ }^{*}\right)\right]$

Figure 10 illustrates joint influences of variations in common cycle time $T_{\mathrm{A}}$ and average overtime added output rate $\bar{\alpha}_{1}$ on $E\left[T C U\left(T_{\mathrm{A}}\right)\right]$. It is noted that the expected system cost raises significantly, as $\overline{\alpha_{1}}$ increases; and $E\left[T C U\left(T_{\mathrm{A}}\right)\right]$ goes up noticeably, as $T_{\mathrm{A}}$ deviates from $T_{\mathrm{A}}$ * (i.e., 0.6248).

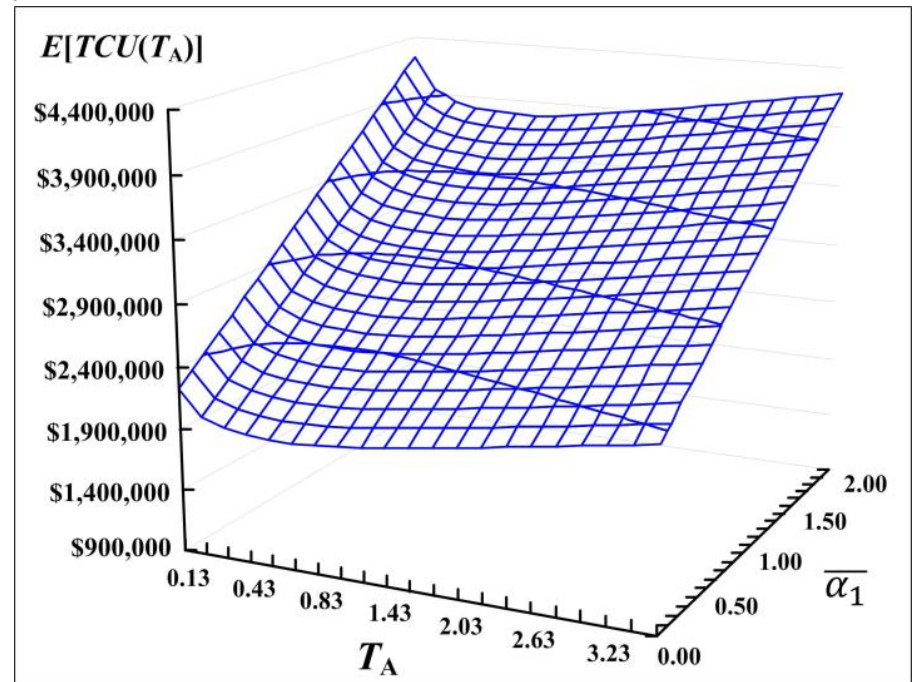

Figure 10. Joint influences of variations in $T_{\mathrm{A}}$ and $\overline{\alpha_{1}}$ on $E\left[T C U\left(T_{\mathrm{A}}\right)\right]$ 
Exploration of a Multi-Product EPQ-Based System with Overtime and Quality Reassurance

Furthermore, the exploratory outcomes on combined effects of changes in average scrap rate $\bar{\varphi}$ and average added percentage of unit cost (due to overtime option) $\overline{\alpha_{3}}$ on $E\left[T C U\left(T_{\mathrm{A}}^{*}\right)\right]$ is exhibited in Figure 11. It can be seen that $E\left[T C U\left(T_{\mathrm{A}}{ }^{*}\right)\right]$ increases, as $\bar{\varphi}$ goes up; and $E\left[T C U\left(T_{\mathrm{A}}{ }^{*}\right)\right]$ boosts up drastically, as $\overline{\alpha_{3}}$ raises.

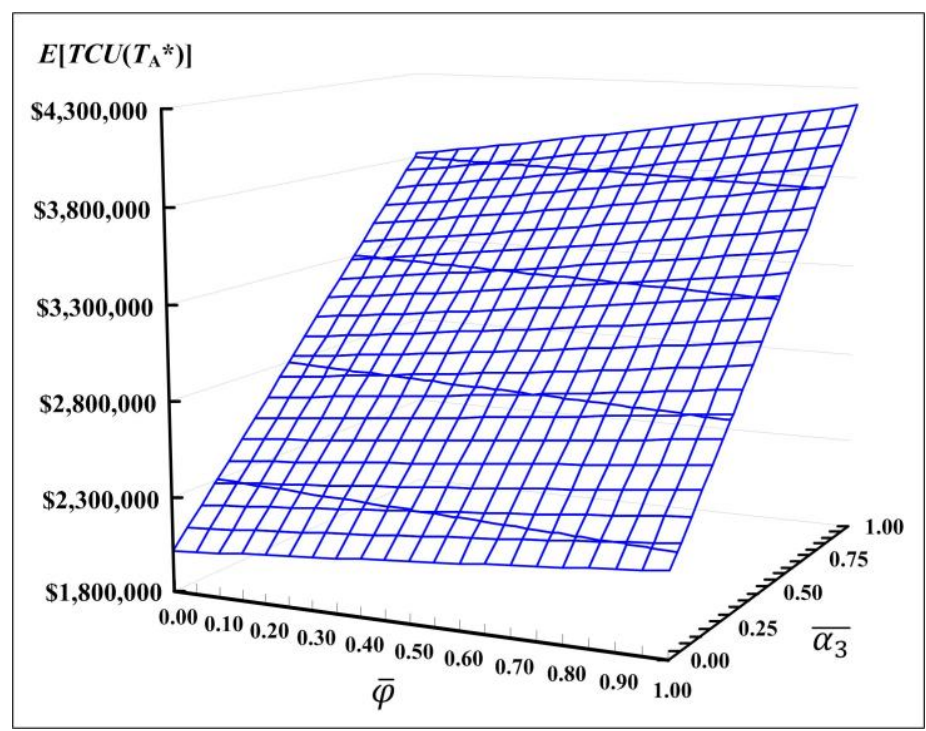

Figure 11. Combined effects of changes in $\bar{\varphi}$ and $\overline{\alpha_{3}}$ on $E\left[T C U\left(T_{\mathrm{A}}{ }^{*}\right)\right.$

\section{Conclusions}

The present study explores a multi-product EPQ model with overtime and product quality reassurance with the objective of finding the optimal stock refilling policy. By employing mathematical techniques, this study successfully develops a model to represent the problem; further, it carries out the derivations needed to find the total cost of the proposed model, and decide the optimal common cycle length that minimizes total cost. By utilizing a numerical illustration, we illustrate that the proposed system can reveal the: (i) influence of variation in overtime-related factors, such as the accelerated output rate and the extra cost associated with it, on the system's variable cost, utilization, and total cost (refer to Table 1 and Figures 4, 6,8 , and 9); (ii) impact of different factors related to product quality (e.g. the non-conformance, rework failure, and overall scrap rates) on the system's total cost (see Figures 5-7); and (iii) combined impact of the changes in overtime- and quality-related factors on various parameters of the system (refer to Figures 10 and 11). The insights obtained from this exploration about important system-related information will be indispensable in improving the planning and control functions of a realistic multi-product refilling system. 
Singa Wang Chiu, Chung-Li Chou, Hong-Dar Lin, Ming-Hon Hwang

\section{ACKNOWLEDGEMENTS}

Authors express their thankfulness to Ministry of Science \& Technology of Taiwan for its support on this project (Funding no. MOST 106-2410-H-324-003)

\section{Appendix - A}

Extra notations of this research are given below (where $i=1,2, \ldots, L$ ):

$t_{1 i \mathrm{~A}}=$ uptime of product $i$

$t_{2 i \mathrm{~A}}=$ rework time of product $i$,

$t_{3 i \mathrm{~A}}=$ downtime of product $i$,

$d_{1 i \mathrm{~A}}=$ production rate of nonconforming product $i$,

$d_{2 i \mathrm{~A}}=$ production rate of scrapped product $i$ in $t_{2 i \mathrm{~A}}$,

$h_{i}=$ unit holding cost of product $i$,

$h_{1 i}=$ unit holding cost of reworked product $i$,

$Q_{i}=$ lot-size of product $i$,

$\varphi_{i}=$ total scrap rate among nonconforming product $i$ in a cycle,

$T_{\mathrm{A}}=$ common production cycle length,

$\mathrm{E}\left[T_{\mathrm{A}}\right]=$ the expected common production cycle length,

$H_{1 i}=$ standing of inventory of completed product $i$ in the end of uptime,

$H_{i}=$ standing of inventory of completed product $i$ in the end of rework,

$I(t)_{i}=$ standing of inventory of completed product $i$ at time $t$,

$I_{\mathrm{D}}(t)_{i}=$ standing of inventory of nonconforming product $i$ at time $t$,

$I_{\mathrm{S}}(t)_{i}=$ standing of scrap stock $i$ at time $t$,

$T=$ common production cycle time in the same system without overtime,

$t_{1 i}=$ standard uptime of product $i$ (without overtime),

$t_{2 i}=$ standard rework time of product $i$,

$t_{3 i}=$ standard downtime of product $i$,

$d_{1 i}=$ standard production rate of nonconforming product $i$,

$d_{2 i}=$ standard production rate of scrapped product $i$ in $t_{2 i \mathrm{~A}}$,

$T C\left(T_{\mathrm{A}}\right)=$ summation of system's cost contributors in a cycle,

$\mathrm{E}\left[T C U\left(T_{\mathrm{A}}\right)\right]=$ the expected sum of system cost per unit time,

$\overline{P_{1 \mathrm{~A}}}=$ the average of $P_{1 \mathrm{~A}}$,

$\overline{P_{1}}=$ the average of $P_{1 i}$,

$\bar{x}=$ the average of $x_{i}$,

$\bar{\varphi}=$ the average of $\varphi_{i}$,

$\overline{C_{\mathrm{A}}}=$ the average of $C_{i \mathrm{~A}}$,

$\bar{C}=$ the average of $C_{i}$,

$\overline{\alpha_{1}}=$ the average of $\alpha_{1 i}$,

$\overline{\alpha_{2}}=$ the average of $\alpha_{2 i}$,

$\overline{\alpha_{3}}=$ the average of $\alpha_{3 i}$. 
Exploration of a Multi-Product EPQ-Based System with Overtime and Quality Reassurance

\section{Appendix - B}

Detailed calculations for $T_{\min }$.

If machine utilization goes higher and the resulting system's idle time becomes smaller, the summation of setup times of $L$ products might not be able to fit in system's idle time. Then, the decision maker has to make sure that $T_{\mathrm{A}}$ is sufficient to comprise the summation of $L$ products' setup, fabrication, and rework times. That is as follows:

$$
T_{\mathrm{A}}>\sum_{i=1}^{L}\left[S_{i}+\left(\frac{Q_{i}}{P_{1 \mathrm{~A}}}\right)+\left(\frac{E\left[x_{i}\right]\left(1-\theta_{1 i}\right) Q_{i}}{P_{2 i \mathrm{~A}}}\right)\right]
$$

Replace $Q_{i}$ with $T_{\mathrm{A}}$ (as shown in Eq. (7)) in Eq. (B-1), one obtains

$$
T_{\mathrm{A}}>\sum_{i=1}^{L}\left[S_{i}+\frac{\lambda_{i} T_{\mathrm{A}}}{P_{1 i \mathrm{~A}}\left[1-\varphi_{i} E\left[x_{i}\right]\right]}+\frac{E\left[x_{i}\right]\left(1-\theta_{1 i}\right) \lambda_{i} T_{\mathrm{A}}}{P_{2 i \mathrm{~A}}\left[1-\varphi_{i} E\left[x_{i}\right]\right]}\right]
$$

or

$$
T_{\mathrm{A}}\left\{1-\sum_{i=1}^{L}\left[\frac{\lambda_{i}}{P_{1 \mathrm{~A}}\left[1-\varphi_{i} E\left[x_{i}\right]\right]}+\frac{E\left[x_{i}\right]\left(1-\theta_{1 i}\right) \lambda_{i}}{P_{2 i \mathrm{~A}}\left[1-\varphi_{i} E\left[x_{i}\right]\right]}\right]\right\}>\sum_{i=1}^{L}\left(S_{i}\right)
$$

or

$$
T_{\mathrm{A}}>\frac{\sum_{i=1}^{L}\left(S_{i}\right)}{1-\sum_{i=1}^{L}\left[\frac{\lambda_{i}}{P_{1 i \mathrm{~A}}\left[1-\varphi_{i} E\left[x_{i}\right]\right]}+\frac{E\left[x_{i}\right]\left(1-\theta_{1 i}\right) \lambda_{i}}{P_{2 i \mathrm{~A}}\left[1-\varphi_{i} E\left[x_{i}\right]\right]}\right]}
$$

Let the right-hand side of Eq. (B-4) be $T_{\min }$, then we obtain the following (see also Eq. (31)):

$$
T_{\min }=\frac{\sum_{i=1}^{L}\left(S_{i}\right)}{1-\sum_{i=1}^{L}\left[\frac{\lambda_{i}}{P_{1 i \mathrm{~A}}\left[1-\varphi_{i} E\left[x_{i}\right]\right]}+\frac{E\left[x_{i}\right]\left(1-\theta_{1 i}\right) \lambda_{i}}{P_{2 i \mathrm{~A}}\left[1-\varphi_{i} E\left[x_{i}\right]\right]}\right]}
$$

and $T_{\mathrm{A}}>T_{\min }$.

\section{Appendix - C}

Table C-1(a): Assumptions of parameters for numerical example with five distinct products

\begin{tabular}{ccccccccccc}
\hline Product \# & $\lambda_{i}$ & $\alpha_{1 i}$ & $P_{1 i}$ & $P_{1 i \mathrm{~A}}$ & $P_{2 i}$ & $P_{2 i \mathrm{~A}}$ & $h_{i}$ & $\alpha_{2 i}$ & $K_{i}$ & $K_{i \mathrm{~A}}$ \\
\hline 1 & 3000 & 0.30 & 58000 & 75400 & 2900 & 3770 & 10 & 0.06 & 10000 & 10600 \\
2 & 3200 & 0.40 & 59000 & 82600 & 2950 & 4130 & 15 & 0.08 & 11000 & 11880 \\
3 & 3400 & 0.50 & 60000 & 90000 & 3000 & 4500 & 20 & 0.10 & 12000 & 13200 \\
4 & 3600 & 0.60 & 61000 & 97600 & 3050 & 4880 & 25 & 0.12 & 13000 & 14560 \\
5 & 3800 & 0.70 & 62000 & 105400 & 3100 & 5270 & 30 & 0.14 & 14000 & 15960 \\
\hline
\end{tabular}


Singa Wang Chiu, Chung-Li Chou, Hong-Dar Lin, Ming-Hon Hwang

\begin{tabular}{cccccccccccc}
\hline & \multicolumn{10}{c}{ Table C-1(b): Continuation of Table C-1(a) } \\
\hline Product \# & $\alpha_{3 i}$ & $C_{i}$ & $C_{i \mathrm{~A}}$ & $C_{\mathrm{R} i}$ & $C_{\mathrm{R} i \mathrm{~A}}$ & $x_{i}$ & $C_{\mathrm{S} i}$ & $h_{1 i}$ & $\theta_{1 i}$ & $\theta_{2 i}$ & $\varphi_{i}$ \\
\hline 1 & 0.15 & 80 & 92 & 50 & 57.5 & $5 \%$ & 20 & 30 & 0.05 & 0.05 & 0.0975 \\
2 & 0.20 & 90 & 108 & 55 & 66.0 & $10 \%$ & 25 & 35 & 0.10 & 0.10 & 0.1900 \\
3 & 0.25 & 100 & 125 & 60 & 75.0 & $15 \%$ & 30 & 40 & 0.15 & 0.15 & 0.2775 \\
4 & 0.30 & 110 & 143 & 65 & 84.5 & $20 \%$ & 35 & 45 & 0.20 & 0.20 & 0.3600 \\
5 & 0.35 & 120 & 162 & 70 & 94.5 & $25 \%$ & 40 & 50 & 0.25 & 0.25 & 0.4375 \\
\hline
\end{tabular}

\section{REFERENCES}

[1] Vergin, R., Lee, T. (1978), Scheduling Rules for the Multiple Product Single Machine System with Stochastic Demand. Information Systems and Operational Research 16(1), 64-73;

[2] Günther, H.O. (1988), Numerical Evaluation of Heuristics for the Multi-Item Single-Level Capacitated Lot-Size Problem. Engineering Costs and Production Economics 14(3), 233-243;

[3] Sox, C.R., Muckstadt, J.A. (1996), Multi-Item, Multi-Period Production Planning with Uncertain Demand. IIE Transactions 28(11), 891-900;

[4] Absi, N., Kedad-Sidhoum, S. (2009), The Multi-Item Capacitated Lot-Sizing Problem with Safety Stocks and Demand Shortage Costs. Computers and Operations Research 36(11), 2926-2936;

[5] Rahmani, D., Ramezanian, R., Fattahi, P., Heydari, M. (2013), A Robust Optimization Model for Multi-Product Two-Stage Capacitated Production Planning Under Uncertainty. Applied Mathematical Modelling 37(20-21), 8957-8971;

[6] Jawla, P., Singh, S.R. (2016), Multi-Item Economic Production Quantity Model for Imperfect Items with Multiple Production Setups and Rework under the Effect of Preservation Technology and Learning Environment. International Journal of Industrial Engineering Computations 7(4), 703-716;

[7] Chiu, S.W., Hsieh, Y-T., Chiu, Y-S.P., Hwang, M-H. (2016), A Delayed Differentiation Multi-Product FPR Model with Scrap and a Multi-Delivery Policy - II: Using Two-Machine Production Scheme. International Journal for Engineering Modelling 29(1-4), 53-68;

[8] Razmi, J., Kazerooni, M.P., Sangari, M.S. (2016), Designing an Integrated Multi-Echelon, Multi-Product and Multi-Period Supply Chain Network with Seasonal Raw Materials. Economic Computation and Economic Cybernetics Studies and Research 50(1),ASE Publishing 273-290;

[9] Zahedi, Z., Ari Samadhi, T.M.A., Suprayogi, S., Halim, A.H. (2016), Integrated Batch Production and Maintenance Scheduling for Multiple Items Processed on a Deteriorating Machine to Minimize Total Production and Maintenance Costs with Due Date Constraint. International Journal of Industrial Engineering Computations 7(2), 229-244;

[10] Chiu, Y-S.P., Liu, C-J., Hwang, M-H. (2017), Optimal Batch Size Considering Partial Outsourcing Plan and Rework. Jordan Journal of Mechanical and Industrial Engineering 11(3), 195-200; 
Exploration of a Multi-Product EPQ-Based System with Overtime and Quality Reassurance

[11] Vujosevic, M., Makajic-Nikolic, D., Pavlovic, P. (2017), A New Approach to Determination of the Most Critical Multi-State Components in Multi-State Systems. Journal of Applied Engineering Science 15(4), 401-405;

[12] Chiu, Y.-S.P., Lin, H.-D., Wu, M.-F., Chiu, S.W. (2018), Alternative Fabrication Scheme to Study Effects of Rework of Nonconforming Products and Delayed Differentiation on a Multiproduct Supply-Chain System. International Journal of Industrial Engineering Computations 9(2), 235-248;

[13] Conley, W. (1985), Production Scheduling with Overtime Considerations. International Journal on Policy and Information 9(1), 149-157;

[14] Shiftan, Y., Wilson, N.H.M. (1994), Absence, Overtime, and Reliability Relationships in Transit Workforce Planning. Transportation Research Part A 28(3), 245-258;

[15] Schank, T. (2005), Are Overtime Plants More Efficient than Standard-Time Plants? A Stochastic Production Frontier Analysis Using The IAB Establishment Panel. Empirical Economics 30(3), 693-710;

[16] Campbell, G.M. (2012), On-Call Overtime for Service Workforce Scheduling when Demand Is Uncertain. Decision Sciences 43(5), 817-850;

[17] Chiu, S.W., Lin, H-D., C-L. Chou, Chiu, Y-S.P. (2018), Mathematical Modeling for Exploring the Effects of Overtime Option, Rework, and Discontinuous Inventory Issuing Policy on EMQ Model. International Journal of Industrial Engineering Computations 9(4), 479-490;

[18] Liu, Y., Wu, H., Hou, J., Wei, C., Ren, W. (2017), An Injection/Production Rate Allocation Method Applied for Polymer-Surfactant Flooding. Journal of Engineering Research 5(2), 250-267;

[19] Chiu, S.W., Wu, H-Y., Chiu, Y-S.P., Hwang, M-H. (2018), Exploration of Finite Production Rate Model with Overtime and Rework of Nonconforming Products. Journal of King Saud University - Engineering Sciences 30(3), 224-231;

[20] Gopalan, M.N., Kannan, S. (1994), Expected Duration Analysis of a Two-Stage Transfer-Line Production System Subject to Inspection and Rework. Journal of the Operational Research Society 45(7), 797-805;

[21] Grosfeld-Nir, A., Gerchak, Y. (2002), Multistage Production to Order with Rework Capability. Management Science 48(5), 652-664;

[22] Sarker, B.R., Jamal, A.M.M., Mondal, S. (2008), Optimal Batch Sizing in a Multi-Stage Production System with Rework Consideration. European Journal of Operational Research 184(3), 915-929;

[23] Chiu, Y-S.P., Hsieh, Y-T., Kuo, J-S. Chiu, S.W. (2016), A Delayed Differentiation Multi-Product FPR Model with Scrap and a Multi-Delivery Policy - I: Using Single-Machine Production Scheme. International Journal for Engineering Modelling 29(1-4), 37-52;

[24] Kaylani, H., Almuhtady, A., Atieh, A.M. (2016), Novel Approach to Enhance the Performance of Production Systems Using Lean Tools. Jordan Journal of Mechanical and Industrial Engineering 10(3), 215-229; 
Singa Wang Chiu, Chung-Li Chou, Hong-Dar Lin, Ming-Hon Hwang

[25] Abubakar, M., Basheer, U., Ahmad, N. (2017), Mesoporosity, Thermochemical and Probabilistic Failure Analysis of Fired Locally Sourced Kaolinitic Clay. Journal of the Association of Arab Universities for Basic and Applied Sciences 24, 81-88;

[26] Chiu, S.W., Liu, C.-J., Chen, Y.-R., Peter Chiu, Y.-S. (2017), Finite Production Rate Model with Backlogging, Service Level Constraint, Rework, and Random Breakdown. International Journal for Engineering Modelling 30(1-4), 63-80;

[27] Khalili, A., Ismail, M.Y., Karim, A.N.M., Che Daud, M.R. (2017), Critical Success Factors for Soft TQM and Lean Manufacturing Linkage. Jordan Journal of Mechanical and Industrial Engineering 11(2), 129-140;

[28] Chiu, Y.-S.P., Chen, H.-Y., Chiu, T., Chiu, S.W. (2018), Incorporating Flexible Fabrication Rate and Random Scrap into a FPR-Based Supply-Chain System. Economic Computation and Economic Cybernetics Studies and Research 52(2),ASE Publishing, 157-174;

[29] Saari, J., Odelius, J. (2018), Detecting Operation Regimes Using Unsupervised Clustering with Infected Group Labelling to Improve Machine Diagnostics and Prognostics. Operations Research Perspectives 5, 232-244;

[30] Nahmias, S. (2009), Production and Operations Analysis. McGraw-Hill Co. Inc., New York. 